\title{
Contrast-enhanced endoscopic ultrasound-guided access to nondilated bile duct
}

Endoscopic ultrasound (EUS)-guided biliary access has recently been indicated not only for malignant biliary obstruction but also for benign biliary stricture [1 4]. Among EUS-guided biliary drainage routes, EUS-guided hepaticogastrostomy (HGS) may be the most challenging procedure because the diameter of the intrahepatic bile duct is smaller than the extrahepatic bile duct. In addition, if the intrahepatic bile duct is not dilated, such as in benign biliary disease, EUS-guided access may be challenging. Recently, EUS-HGS under contrast-enhanced EUS has been reported as a novel technique [5]. The concept of this technique is to obtain a clear image of the bile duct. We herein describe technical tips for contrast-enhanced EUS-guided access to a nondilated bile duct.

A 55-year-old woman was admitted to our hospital because of liver abscess. She had undergone pancreaticoduodenostomy for intraductal papillary mucinous neoplasm 3 years previously. She also experienced frequent cholangitis due to hepaticojejunum stricture (HJS), which can lead to liver abscess. The liver abscess was treated by percutaneous transhepatic abscess drainage. After this procedure, an EUS-guided approach was attempted to treat the HJS ( $\nabla$ Video 1 ).

Dilatation of the intrahepatic bile duct was not observed ( $\triangleright$ Fig. 1 a). To detect the biliary tracts, sonographic contrast agent (Sonazoid; Daiichi-Sankyo, Tokyo, Japan) was intravenously administered. The narrow intrahepatic bile duct was visualized (> Fig.1 b). This bile duct was carefully punctured using a 19-gauge aspiration needle. Bile juice could not be aspirated. A small amount of normal saline was injected, and because no resistance to the injection was observed, the contrast medium was injected ( $\mathbf{F i g . 2} \mathbf{a}$ ). Finally, a covered metal stent was deployed from the intrahepatic bile duct to the stomach without any adverse events ( Fig. 2b,c).

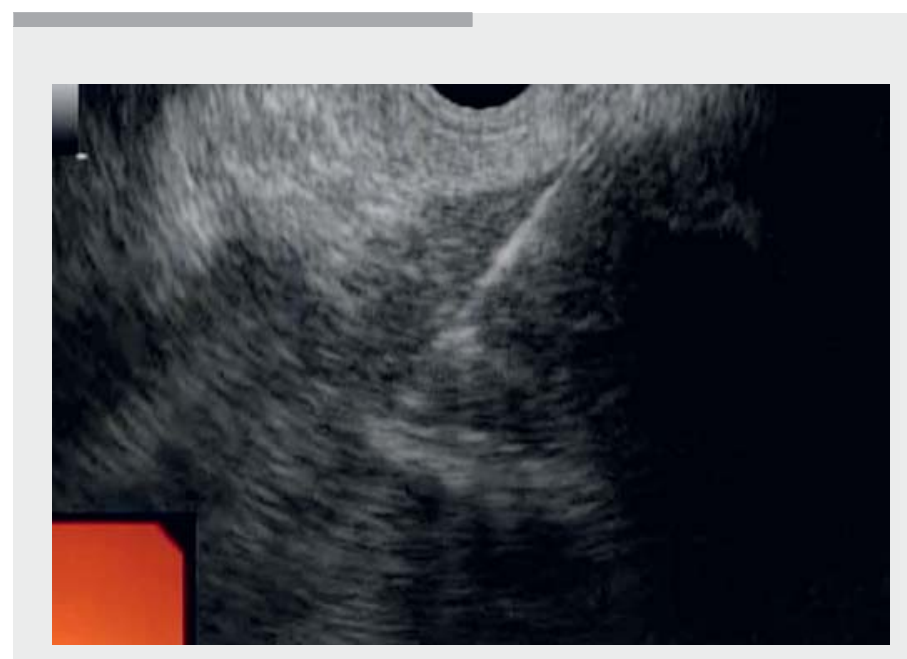

- Fig. 1 Endoscopic ultrasound imaging. a The intrahepatic bile duct was not dilated. b After intravenous administration of sonographic contrast agent, the narrow intrahepatic bile duct was visualized (arrow).

Contrast-enhanced EUS-guided biliary drainage has clinical impact not only for obtaining a clear image of the bile duct but also in cases of nondilated bile ducts.

Endoscopy_UCTN_Code_TTT_1AS_2AD 

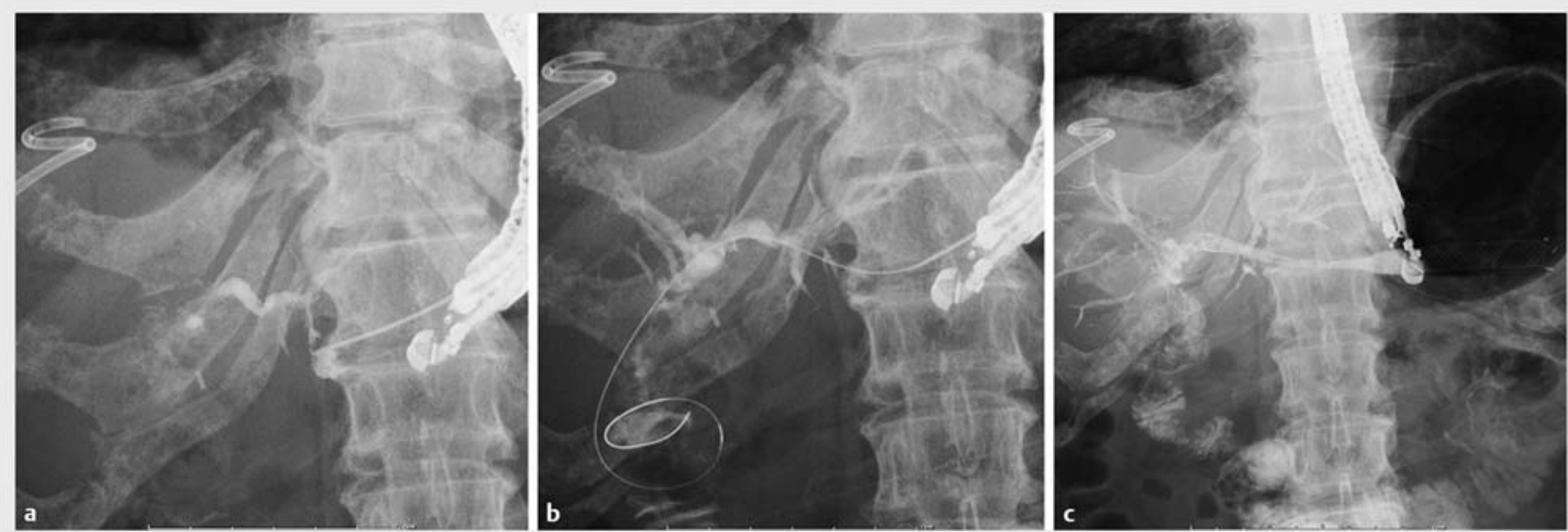

Fig. 2 Contrast enhancement. a The contrast medium was injected and a cholangiogram was successfully obtained. b A 0.025 -inch guidewire was successfully inserted into the biliary tract. c A covered metal stent was deployed from the intrahepatic bile duct to the stomach.

Competing interests

None

The authors

Takeshi Ogura, Tadahiro Yamada, Masanori Yamada, Nobu Nishioka, Kazuhide Higuchi 2nd Department of Internal Medicine, Osaka Medical College, Osaka, Japan

\section{Corresponding author}

\section{Takeshi Ogura, MD}

2nd Department of Internal Medicine, Osaka Medical College, 2-7 Daigakuchou, Takatsukishi, Osaka 569-8686, Japan Fax: +81-72-6846532

oguratakeshi0411@yahoo.co.jp

\section{References}

[1] Mukai S, Itoi T, Sofuni A et al. EUS-guided antegrade intervention for benign biliary disease in patients with surgically altered anatomy (with videos). Gastrointest Endosc 2019; 89: 399-407

[2] James TW, Fan YC, Baron TH. EUS-guided hepaticogastrostomy as a portal to allow definitive antegrade treatment of benign biliary disease in patients with surgically altered anatomy. Gastrointest Endosc 2018; 88: $547-554$

[3] Itoi T, Sofuni A, Tsuchiya T et al. Endoscopic ultrasonography-guided transhepatic antegrade stone removal in patients with surgically altered anatomy: case series and technical review (with videos). J Hepatobiliary Pancreat Sci 2014; 21: E86-E93

[4] Kamiyama R, Ogura T, Okuda A et al. Electrohydraulic lithotripsy for difficult bile duct stones under endoscopic retrograde cholangiopancreatography and peroral transluminal cholangioscopy guidance. Gut Liver 2018; $15: 457-462$

[5] Minaga K, Kitano M, Yoshikawa T et al. Hepaticogastrostomy guided by real-time contrast-enhanced harmonic endoscopic ultrasonography: a novel technique. Endoscopy 2016; 48: E228 -E229

\section{Bibliography}

DOI https://doi.org/10.1055/a-0885-9722

Published online: 2.5.2019

Endoscopy 2019; 51: E211-E212

(c) Georg Thieme Verlag KG

Stuttgart · New York

ISSN 0013-726X

\section{ENDOSCOPY E-VIDEOS}

https://eref.thieme.de/e-videos

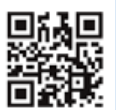

Endoscopy E-Videos is a free access online section, reporting on interesting cases and new techniques in gastroenterological endoscopy. All papers include a high quality video and all contributions are freely accessible online.

This section has its own submission website at https://mc.manuscriptcentral.com/e-videos 